\title{
elyra
}

\section{Poemas como colagens, colagens como retratos: Carlos de Oliveira e Pedro Mexia}

\author{
Teresa Jorge Ferreira \\ Bolseira de Doutoramento da Fundação para a Ciência e a Tecnologia \\ Instituto de Estudos de Literatura e Tradição \\ Faculdade de Ciências Sociais e Humanas da Universidade Nova de Lisboa
}

Resumo: A colagem poética é sobretudo associada às vanguardas do século $X X$, mas a sua prática teve um alcance mais amplo. Considerando que, a partir do século $X X$, a escrita de autorretratos poéticos foi intensamente explorada, este estudo pretende questionar de que modo a técnica da colagem contribuiu para a reflexão poética sobre o autorretrato. Com este propósito, serão confrontados os textos "Retrato do autor por Camilo Pessanha (colagem)", de Carlos de Oliveira, e "Auto-retrato com versos de Camões", de Pedro Mexia, observando como os poemas citam outros autores para criar um retrato autoral, que nunca se dissocia da própria ideia de trabalho poético.

Palavras-chave: Poema, Autorretrato, Colagem, Carlos de Oliveira, Pedro Mexia

\begin{abstract}
Poetic collage is mainly connected to the $20^{\text {th }}$ century avant-garde, but its practice had a larger impact. Considering that, in the $20^{\text {th }}$ century, the writing of poetic self-portraits was intensely explored, this study aims to reflect upon the contributions of collage to the poetic self-portrait. To this end, the poems "Retrato do autor por Camilo Pessanha (colagem)", by Carlos de Oliveira, and "Auto-retrato com versos de Camões", by Pedro Mexia, will be read side by side, showing how the poets cite other poets in order to create a portrait of themselves as authors, which is never separate from their own conception of poetic work.
\end{abstract}

Keywords: Poem, Self-portrait, Collage, Carlos de Oliveira, Pedro Mexia 
Lavoisier

Na poesia

natureza variável

das palavras,

nada se perde

ou cria,

tudo se transforma:

cada poema,

no seu perfil

incerto

e caligráfico,

já sonha

outra forma.

Carlos de Oliveira

(Oliveira 2003: 201)

Para refletir sobre as implicações da colagem na composição de autorretratos poéticos, atentemos em dois textos de Carlos de Oliveira e de Pedro Mexia que solicitam uma leitura conjunta.

Carlos de Oliveira publica, em 1950, o livro Terra de Harmonia, e, em 1976, a antologia Trabalho Poético, com poemas reescritos e poemas inéditos, na qual inclui no conjunto de Terra de Harmonia o "Retrato do autor por Camilo Pessanha (colagem)", até então inédito:

A cinza arrefeceu sobre o brasido

das coisas não logradas ou perdidas:

olhos turvos de lágrimas contidas,

eu vi a luz em um país perdido. (Oliveira 2003: 139) 
Em 2007, Pedro Mexia publica no livro Senhor Fantasma o poema "Auto-retrato com versos de Camões" (escrito no início da década de 1990; Ribeiro 2011), depois incluído na sua antologia de 2011, Menos por menos:

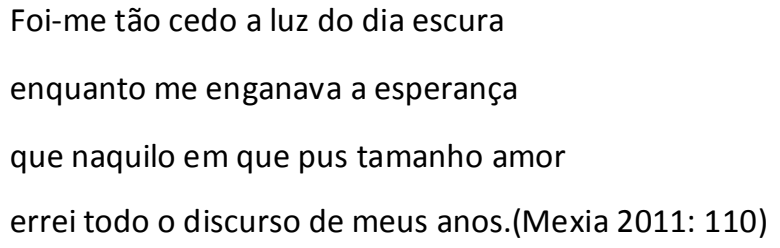

Estes dois textos têm afinidades flagrantes: ambos os títulos prometem retratos e referem os nomes de outros poetas; ambos os poemas são quadras com versos decassílabos retirados de quatro poemas distintos de cada um dos autores mencionados; ambos os retratos apresentam semelhanças estratégicas e proximidades semânticas (incluindo, por exemplo, a palavra "luz").

\section{Os títulos}

Os títulos constituem o único elemento textual do conjunto que é da autoria inequívoca dos poetas, sendo o corpo dos poemas composto por versos (selecionados e organizados) retirados de poemas de um outro autor. Os títulos, porque se leem antes, apresentam o poema e preparam o leitor para os versos que se seguem - pressupõem assim um leitor e sublinham a "autoridade interpretativa" do autor (Ferry 1996: 2-3).

Carlos de Oliveira apresenta um "Retrato do autor" e Pedro Mexia um "Autoretrato". "Retrato do autor" é já em si uma citação de uma prática de títulos usada sobretudo nas artes plásticas a partir do Renascimento e depois estendida à literatura. A partir do século XIX, foi-se tornando mais comum a utilização de "auto-retrato" em várias línguas (com a ortografia atual em português: "autorretrato"), palavra que apareceu pela primeira vez num dicionário de língua portuguesa em 1949, como "retrato de uma pessoa, feito por si própria", sendo que o significado de "retrato" incluía já a "descrição oral ou escrita". A utilização de expressões diferentes pelos dois poetas pode ser um sinal dessa evolução do uso e consequente dicionarização da palavra, mas tem também implicações quanto ao problema da autoria, um problema-chave da técnica da colagem, já que um 
"retrato do autor por outro autor" é diferente de um "auto-retrato com versos de outro autor". Atualmente, e graças ao desenvolvimento editorial dos últimos séculos, assume-se que a atribuição de títulos é sempre feita pelos autores dos poemas. Até ao século XVIII, os títulos eram normalmente atribuídos pelo editor ou por alguém que conhecesse a obra, sendo frequentes os títulos que mencionavam o autor na terceira pessoa. $\mathrm{O}$ facto de alguns títulos atuais continuarem a seguir essa tradição acrescenta alguns problemas de interpretação que não existiam anteriormente (Ferry 1996: 19). Se Carlos de Oliveira publica um poema cujo título é "Retrato do autor por Camilo Pessanha", e sendo esse título escrito por ele, podemos pensar em várias hipóteses, sendo a mais imediata a de que se trata do retrato do autor Carlos de Oliveira. Seguindo esta hipótese, observa-se que Carlos de Oliveira está a referir-se a ele próprio enquanto autor na terceira pessoa: a única frase escrita pelo autor é escrita como se não fosse escrita por ele. Este título também atribui a autoria do retrato a Camilo Pessanha, como se o título fosse escolhido pelo editor da obra (diferente do autor) para um poema do autor. Ora, o título sublinha assim o papel do poeta como leitor e editor crítico da sua própria obra (aspeto muito relevante em Carlos de Oliveira, que reapresenta cuidadosamente a sua obra ao longo das edições: "O autor remodelou, incluiu, cortou (sobretudo cortou) o que lhe pareceu necessário para alcançar um conjunto mais equilibrado"; Oliveira 2003: 373), ao mesmo tempo que reforça a distância crítica entre o "autor" do poema e o "eu" do poema:

the distinction in grammatical persons between the he of the title and the $I$ of the verses is an authoritative representation (made by the author of both) of the critical distance between the actual poet and the created figure whose voice we hear in the poem. (Ferry 1996: 19)

O título de Pedro Mexia não apresenta o problema da autoria da mesma forma: o retrato não é feito "por" Camões, mas "com versos de" Camões. Ou seja, o primeiro título declara que o retrato de Carlos de Oliveira é feito "por" Camilo Pessanha: propondo um hetero-autorretrato; o segundo indica que o retrato de Pedro Mexia é feito "com versos de" Camões: sugerindo um auto-heterorretrato. Em ambos os casos, no entanto, se podem multiplicar as hipóteses interpretativas num jogo de espelhos intrapoético que aprofunda o sentido da citação. 
Ora, estes títulos pressupõem um leitor (funcionam como pista interpretativa dos versos); pressupõem também um autor (responsável pelos títulos e pela construção dos poemas); e pressupõem ainda um autor-leitor (que refere no título não o seu próprio nome, mas o nome do autor que foi lido). Carlos de Oliveira leu Camilo Pessanha, viu ou leu "retratos de autor", viu ou leu "colagens". No caso de Carlos de Oliveira, o título menciona de forma expressa a técnica da "colagem", entre parênteses, como subtítulo depois de "Retrato do autor por Camilo Pessanha": "colagem" é também uma técnica que se desenvolveu nas artes plásticas com as vanguardas do século XX e que rapidamente se transferiu para a literatura. No entanto, neste poema de Carlos de Oliveira, não há elementos visuais de colagem. O autor faz referência a uma técnica vanguardista, usada como analogia na poesia, mas o que há de facto é uma composição de citações textuais, de versos "copiados". Pedro Mexia menciona expressamente os "versos", dando mais ênfase ao que é "recortado" do que à operação de "colagem". Estes dois poetas assumem assim uma herança de elementos variados: sonetos, retratos, colagens, poemas como retratos, e, no caso de Pedro Mexia, retratos como colagens, uma vez que Mexia é já um leitor de Carlos de Oliveira, fazendo um pastiche formal da colagem, apesar de não o referir explicitamente.

\section{As colagens}

Os referidos poemas de Carlos de Oliveira e de Pedro Mexia chegam-nos como o resultado da seleção de versos de Camilo Pessanha e de Luís de Camões e da sua composição num novo todo, como citação em forma de quadra. Não há enxerto de versos de outro autor num conjunto de versos do autor da citação: todos os versos são de outro poeta. Não há também utilização de materiais originalmente "não-poéticos", como títulos de jornais ou slogans publicitários. A analogia com a colagem em artes plásticas é expressiva, mas neste processo a utilização da tesoura e da cola é apenas metafórica, já que, se os autores usaram estes utensílios no seu lugar de trabalho, isso não é manifesto no resultado publicado. Carlos de Oliveira enumera num texto de $O$ Aprendiz de Feiticeiro os elementos necessários para o seu "trabalho oficinal", não mencionando a tesoura e a cola, mas sublinhando a importância da paciência e da consciência: “Mesa, papel, caneta, luz eléctrica. E horas sobre horas de paciência, consciência profissional" (Oliveira 2004: 185). Nestes 
poemas, não há assim um efeito visual relevante na folha de papel, como se pode observar noutras colagens poéticas (recordem-se os poemas visuais ligados à revista Poesia Experimental). O processo para a composição destes poemas é de citação e nesse sentido implica seleção (leitura) e composição (escrita), "prélêvement" e "greffe", como refere Antoine Compagnon em La seconde main ou le travail de la citation (Compagnon 1979: 29). Compagnon vai mais longe ao dizer que "toute l'écriture est collage et glose, citation et commentaire" (Compagnon 1979: 32), partindo das máximas "Nous ne faisons que nos entregloser" (Montaigne), "Parler, c'est tomber dans la tautologie" (Borges) e "Non nova, sed nove" (apud Compagnon 1979: 9-12). Não recusando esta generalização que exprime bem a força da intertextualidade, podemos observar o modo particular como a citação é feita nestes dois poemas de Carlos de Oliveira e de Pedro Mexia.

Os quatro versos de "Retrato do autor por Camilo Pessanha (colagem)" são retirados dos seguintes poemas: "[Ó meu coração, torna para trás.]" (Pessanha 2000: 48) ("A cinza arrefeceu sobre o brasido"); “[Olvido]" (Pessanha 2000: 23) ("das coisas não logradas ou perdidas:"); "[Quando voltei encontrei os meus passos]" (Pessanha 2000: 41) ("olhos turvos de lágrimas contidas,"); “[Inscrição]" (Pessanha 2000: 17-19) ("eu vi a luz em um país perdido."). Curiosamente, os títulos dos poemas de Pessanha mencionados têm sofrido algumas variações editoriais, não havendo a certeza, em muitos casos, de que tenham sido atribuídos pelo autor, o que vai ao encontro das reflexões de Anne Ferry já mencionadas. Os quatro versos de "Auto-retrato com versos de Camões" são, por sua vez, retirados dos sonetos que começam da seguinte forma: "No mundo, poucos anos e cansados" (Camões 1990: 258) ("Foi-me tão cedo a luz do dia escura"); "Foi já um tempo doce cousa amar," (Camões 1990: 17) ("enquanto me enganava a esperança"); "Que poderei do mundo já querer," (Camões 1990: 222) ("que naquilo em que pus tamanho amor"); "Erros meus, má fortuna, amor ardente" (Camões 1990: 244) ("errei todo o discurso de meus anos.").

Os poemas de Carlos de Oliveira e de Pedro Mexia não usam diferentes tipos de letra nem aspas para destacar a citação, o que deixa ao leitor, caso não conheça os versos citados de memória, o trabalho de pesquisa para verificar como é feita a citação (se são palavras isoladas, fragmentos de versos, versos inteiros, dísticos, tercetos, etc.). A utilização das aspas seria uma forma de deixar o texto visivelmente "cicatrizado", recorrendo mais uma vez a 
Compagnon ("la cicatrice elle-même (les guillemets)"; Compagnon 1979: 32). O sinal tipográfico criaria uma distância maior em relação às palavras dos outros poetas, mas aqui a apropriação dos quatro versos é trabalhada como um todo coerente e sintaticamente correto, sendo verosímil que o texto tivesse sido escrito assim "de raiz". Para quebrar a estranheza que poderia resultar da leitura de um "poema cosido com retalhos", com "costuras" visíveis, não só é feita uma atualização ortográfica (que pode também resultar das próprias edições consultadas ou da memorização dos versos), como são adaptados os sinais de pontuação e as maiúsculas ao novo conjunto sintático. Apesar de ser impossível estabelecer com rigor estas diferenças, uma vez que poderão variar consoante as edições de cada um dos autores, podemos arriscar algumas. No caso de Carlos de Oliveira, notam-se as seguintes adaptações relativamente à edição de Clepsydra de 2000 organizada por Gustavo Rubim: no primeiro verso, o ponto final foi substituído por uma vírgula e o " $\mathrm{z}$ " foi substituído por "s" em "brasido"; no segundo verso, a maiúscula inicial desapareceu e o ponto final foi substituído por dois pontos; no terceiro verso, a maiúscula inicial desapareceu e o ponto final foi substituído por vírgula; no quarto verso, a maiúscula inicial desapareceu. No caso de Pedro Mexia, o poema "colado" tem apenas uma maiúscula no início e um ponto final no final, o que não corresponde às edições consultadas dos sonetos de Camões, em que também existem diferenças na pontuação e na utilização das maiúsculas, além de variantes na fixação do texto.

A parataxe que se possa verificar nestes poemas não é um elemento obviamente resultante da colagem, uma vez que há estruturas sintáticas regulares que não são quebradas de forma violenta pela justaposição dos versos. O poema de Carlos de Oliveira transforma o segundo verso no complemento direto da oração do primeiro; o terceiro verso funciona como complemento circunstancial (de sintagma preposicional, apesar da elipse de "com") relativamente à oração do quarto verso (ou seja, invertendo a ordem, ficaria: "eu vi a luz em um país perdido [com] os olhos turvos de lágrimas contidas"). No caso de Pedro Mexia, há uma organização de orações por meio de subordinações, aproveitando os vocábulos "enquanto" e "que", notando-se uma maior complexidade na construção sintática. Neste sentido, os dois poemas contrariam o que Marjorie Perloff aponta como pontos fundamentais da colagem verbal: 
Coordination rather than subordination, likeness and difference rather than logic or sequence or even qualification - here are the elements of verbal collage. (Perloff 1998)

Pedro Mexia, associado à poética pós-moderna do mínimo e do quotidiano (assentando a sua escrita num "exercício associativo" que parte de "vestígios" e de "breves episódios"; Martelo 2001: 492-493), faz, no entanto, a colagem com versos de Camões (o poeta inquestionável do cânone, que dá por antonomásia o nome à língua portuguesa), não indo mais uma vez ao encontro das considerações de Perloff sobre a "pós-colagem":

The shift in such "post-collage" works is from the juxtaposition of carefully chosen citations or statements [...] to a focus on the inherent poetic and artistic possibilities of the "ordinary", the "everyday" as in the contemporary poetry and fiction [...]. (Perloff 1998)

Outro fator que contribui para a coerência das composições é o facto de ambos os poemas apresentarem os verbos no pretérito perfeito ("arrefeceu", "vi", "foi", "pus", "errei") e imperfeito ("enganava"). A quadra de Carlos de Oliveira tem rima interpolada e a de Pedro Mexia tem apenas versos soltos. Todos os versos dos dois poemas são decassílabos e todos são heroicos (com as sílabas tónicas nas posições 6 e 10), excetuando o último do poema de Carlos de Oliveira, que é sáfico (com as sílabas tónicas nas posições 4,8 e 10). Curiosamente, é também este o único verso que não é retirado de um soneto. $O$ facto de os restantes o serem contribui também para a coerência rítmica do conjunto. Este verso, "eu vi a luz em um país perdido", é o primeiro da quadra de Camilo Pessanha, usualmente intitulada de "Inscrição" (apesar de esta palavra funcionar mais como "cortina" no conjunto do livro do que como título, uma vez que não aparece imediatamente acima do poema, mas na página anterior), que abre a obra Clepsydra. É o primeiro verso do primeiro poema de uma primeira inscrição (que pode ser considerada uma "autoinscrição"), um verso tão marcante da nossa poesia que é quase um emblema, que serve aqui de último verso ao "Retrato do autor por Camilo Pessanha".

\section{Os retratos}

Os dois poemas transcritos no início são apresentados nos respetivos títulos como retratos, mas quantos retratos são possíveis a partir destes dois textos? Os poemas abrem-se a 
múltiplas leituras. São retratos de Carlos de Oliveira, de Camilo Pessanha, de Pedro Mexia, de Camões? São retratos da figura do autor, do autor-leitor? São retratos do próprio poema? Retratos do autorretrato poético?

A prosopopeia criada no texto é ambígua, o "eu" do poema são vários "eus", ou não é nenhum, mas as propostas dos títulos citam o que já é um "lugar-comum" artístico: "Retrato do autor" ou "Auto-retrato". Michel Beaujour, em Miroirs d'encre, refletindo sobre o autorretrato literário, discorre em relação à pergunta "quem sou eu?", dizendo que o autorretratista tem de deslocar a questão ou de procurar outras respostas: "je suis cette fragmentation, cet éparpillement [...]. Je suis, par exemple, mes 'styles', mon 'écriture', mon 'texte'. Ou plus radicalement encore : je suis style, écriture, texte" (Beaujour 1980: 344). É curioso notar que, com a nova ortografia de "autorretrato" em português (com dois erres e sem hífen), a palavra inclua os elementos "autor" e "retrato" - mais do que "auto"-"retrato" (que remete para um incógnito "si próprio"), um autorretrato é um "retrato do autor": do estilo, da escrita, do texto. Neste sentido, estes dois poemas podem ser lidos como artes poéticas, ao proporem um modo específico de fazer poesia, valorizando a riqueza da tradição, usando uma técnica vanguardista com versos canónicos, propondo uma ideia de poesia como renovação do que já foi dito, como trabalho sobre uma herança. Para Beaujour, que estuda textos em prosa que designa como autorretratos (Essais, de Montaigne, L'âge d'homme, de Leiris, etc.), cada autorretrato é escrito como se fosse único no seu género (“Chaque autoportrait s'écrit come s'il était unique en son genre”, Beaujour $1980: 8$ ), mas será assim no caso dos autorretratos poéticos? Se pensarmos no "Auto-retrato" de Alexandre O'Neill (que parodia o soneto de Bocage), no "Auto-retrato" de Ana Hatherly (que parafraseia o soneto de Sóror Violante do Céu), ou no "Retrato do artista em cão jovem" de António José Forte (que cita o Retrato do Artista quando Jovem de James Joyce e o Retrato do Artista quando Jovem Cão de Dylan Thomas), temos exemplos expressivos de poemas que sugerem que os autorretratos poéticos procuram dialogar com outros textos afins. Um ponto fundamental dos retratos de Carlos de Oliveira e de Pedro Mexia é que os autores revelam explicitamente que são também leitores, conscientes da tradição em que se inscrevem. Graham Allen, em Intertextuality, obra que traça uma "história" do conceito de "intertextualidade", refletindo sobre as suas implicações na pós-modernidade, refere que: 
intertextuality reminds us that all texts are potentially plural, reversible, open to the reader's own presuppositions, lacking in clear and defined boundaries, and always involved in the expression or repression of the dialogic 'voices' which exist within society. A term which continually refers to the impossibility of singularity, unity, and thus of unquestionable authority, intertextuality remains a potent tool within any reader's theoretical vocabulary. (Allen 2000: 209)

A intertextualidade, na qual se inclui a citação, revela assim, segundo este estudo, a impossível singularidade e unidade de um texto. No entanto, estes textos de Carlos de Oliveira e de Pedro Mexia expõem a tensão entre a unicidade do poema e a multiplicidade da poesia. Podemos aceitar a aporia: estes autorretratos são únicos na forma como respondem ao apelo da leitura com uma reescrita; são únicos ao mesmo tempo que admitem a possibilidade de haver outros retratos "por" ou "com versos de" outros poetas, ou com versos próprios; são únicos ao mesmo tempo que se abrem a possibilidades infinitas de escolha e de combinação. Não são como os Cent mille milliards de poèmes de Raymond Queneau, que, valorizando também a tradição (pela utilização dos sonetos), exploram a potencialidade dos textos permitindo ao leitor que faça as combinações que quiser com os versos apresentados nas vinte páginas (Sánchez 2012: 163). No caso português, os dois autores propõem uma forma fixa de composição dos versos, legível e memorizável, ao contrário das combinações desmedidas do poemário de Queneau, que não poderiam sequer ser lidas numa vida (Sánchez 2012: 167).

Recordemos as duas palavras que Derrida sugere em Che $\cos ^{\prime} e ̀$ la poesia para uma definição de poesia: "coração" ("saber de cor") e "elipse". Por um lado, os poemas compostos por Carlos de Oliveira e Pedro Mexia são poemas curtos, facilmente memorizáveis; por outro lado, resultam da lembrança de versos de outros poetas, como se esses versos fossem a condensação dos poemas de onde foram copiados. O trabalho de construção destas "colagens" é assim feito com a memória e a citação, com a elipse e o coração. A ideia de trabalho poético proposta nestes poemas é indissociável do trabalho de leitura e citação:

La notion de travail est riche: c'est la puissance en acte, le pouvoir symbolique ou magique de la parole [...]; c'est le "labeur", selon le terme favori de Mallarmé pour désigner ses travaux linguistiques [...]. Je travail la citation comme une matière qui m'habite; et, m'occupant, elle me travaille; non que 
je sois gros de citations ni tourmenté par elles, mais elles m'ébranlent et me provoquent, elles déplacent une force, ne serait-ce que celle de mon poignet, elles mettent en jeu une énergie. (Compagnon 1979: 36)

A reflexão de Compagnon toca em dois aspetos fundamentais que interessa aqui sublinhar: o movimento (energia) que está implicado no trabalho da citação; a reciprocidade (dialógica, especular) com que o autor trabalha a citação e é trabalhado por ela. O autor lê os textos do passado, mas os textos do passado também "leem" o autor. Não é demais recordar que o verbo "citar" vem do latim citāre, significando "pôr em movimento", "chamar, convocar".

Carlos de Oliveira, ao "convocar" Camilo Pessanha no seu retrato, está a trabalhar a poesia de Pessanha ao mesmo tempo que é trabalhado por ela. Está a responder a um apelo de leitura da poesia de Pessanha ao mesmo tempo que apela à leitura da sua própria poesia. O facto de escolher o primeiro verso da "[Inscrição]" é significativo, já que, como assinala Gustavo Rubim, este texto sugere "a assimetria que permite desencadear o movimento (esse sim, potencialmente infinito) que é o único destino de todas as inscrições: o movimento da leitura" (Rubim 1998: 41). Pedro Mexia, por sua vez, responde ao apelo de Carlos de Oliveira, "convocando" Camões no seu autorretrato, explorando novas possibilidades combinatórias, apropriando-se de uma poesia que já se tinha apropriado de outra, como sugere Luís Filipe Parrado ("enquanto criador de uma escrita própria, Oliveira sabe que esta existe para ser apropriada por outros"; Parrado 1996: 195). Os poemas são "apanhados" como o ouriço de Derrida e são novamente lançados para a estrada, expondose ao acidente (Derrida 2003: 9). E estes dois autores retratam-se nesse trabalho poético de movimento e reciprocidade, de exposição ao perigo.

Quem é então o "eu" que fala nos poemas? É a voz do poema?, como propõe Gustavo Rubim a propósito de "[Inscrição]", ao declarar que "[i]nscrito, o "eu" que fala no poema fala como se fosse a voz do poema, a qual não é voz (nem 'eu') senão por figura" (Rubim 1998: 42). O poema só pode ser apropriado porque não tem um sujeito unívoco:

Sem sujeito: há talvez poema, e talvez ele se deixe, mas nunca o escrevo. Um poema, nunca o assino. O outro assina. O eu apenas existe em função da vinda desse desejo: aprender de cor. Tendido para se resumir ao seu próprio suporte, e portanto sem suporte exterior, sem substância, sem sujeito, 
absoluto da escrita em si, o "de cor" deixa-se eleger além do corpo, do sexo, da boca e dos olhos, apaga os bordos, escapa às mãos, mal o consegues ouvir mas ele ensina-nos o coração. (Derrida 2003:

10)

E a citação problematiza a questão do sujeito de forma radical, porque "[I]e sujet de la citation est un personnage équivoque qui tient à la fois de Narcisse et de Pilate. [...] En un sens, il n'y a de sujet de la citation qu'en régime démocratique de l'écriture" (Compagnon 1979: 40). Para exemplificar esta questão de forma mais drástica a propósito destes dois poemas, refira-se que o seguinte soneto de Camões (cujo terceiro verso é usado por Pedro Mexia no seu "Auto-retrato") é antecedido em algumas edições pela dedicatória "A Pêro Moniz, que morreu no mar do monte Félix, em epitáfio", e escrito como "autoepitáfio" do soldado companheiro de Camões:

\footnotetext{
No mundo, poucos anos e cansados

vivi, cheios de vil miséria dura;

foi-me tão cedo a luz do dia escura

que não vi cinco lustros acabados.
}

Corri terras e mares apartados,

buscando à vida algum remédio ou cura;

mas aquilo que, enfim, não quer Ventura,

não o alcançam trabalhos arriscados.

Criou-me Portugal na verde e cara

pátria minha Alenquer; mas ar corruto, que neste meu terreno vaso tinha,

me fez manjar de peixes em ti, bruto mar, que bates na Abássia fera e avara, tão longe da ditosa pátria minha! (Camões 1990: 258)

Este poema, que deu azo a polémica graças às leituras biográficas que se fizeram, assumindo o "eu" do poema como o "eu" de Camões, é usado por Mexia reforçando essa ambiguidade pronominal. 
No entanto, a multiplicidade de "eus" que pode caber no pronome "eu" não nos proíbe de procurar a autorreferencialidade nestes poemas - podemos até ler nos próprios títulos dos poemas um convite nesse sentido. Regressando à "[Inscrição]" de Pessanha, Fernando Cabral Martins, por exemplo, defende que a "'Inscripção' é aí claramente legível como uma apresentação do rosto. E recordemos que os livros da época tinham muitas vezes o retrato do Autor a abrir". Cabral Martins propõe uma interpretação do poema como sugestão simbolista da experiência do ópio ("luz"), do estado físico de prostração ("alma [...] lânguida e inerme") e da vivência na China ("país perdido"), apesar de admitir outras leituras para os quatro versos (apud Rubim 1998: 39-40). Luís Filipe Parrado, por exemplo, entende o "país perdido" de Pessanha como o Portugal "mítico" (Parrado 1996: 188). No caso do poema de Carlos de Oliveira, podemos também defender esta "apresentação do rosto", sendo que um dos versos escolhidos menciona expressamente os "olhos turvos de lágrimas contidas", revelando assim um rosto comovido perante o "país perdido". A proposta de que este "país perdido", sem nome, é Portugal e de que o poema apresenta um sujeito preocupado com país "real" pode parecer previsível, conhecendo-se a ligação de Carlos de Oliveira ao Neorrealismo (e havendo várias referências na sua poesia a "Portugal" e à "pátria"). No entanto, é significativo pensar que o poema não foi incluído em Terra de Harmonia, foi "esquecido", como assinala Luís Filipe Parrado: "este esquecimento (não importando se casual ou causado...) poderá ser lido como hesitação ou sintoma da radicalidade do gesto de o poeta se auto-retratar por meio de palavras dos outros" (Parrado 1996: 183-184). Ora, a ausência do poema no primeiro conjunto pode dever-se, como propõe Parrado, a esta vacilação perante a escrita de um autorretrato com versos alheios, mas pode também revelar pudor em afirmar um rosto, uma individualidade lírica, num tempo de militância ideológica e de inquietações sociais, acrescendo que na edição de 1950 já aparecia, em tiragem especial, um "retrato do autor por Armindo Rodrigues" e um "autógrafo do autor" (Oliveira 2003: 376; Oliveira 1950: 4). A quadra esteve "desaparecida" durante vários anos, não sendo possível verificar se foi reescrita ou não por Carlos de Oliveira entre a década de 1950 e a de 1970.

Na verdade, este poema, lido como autorretrato do poeta Carlos de Oliveira, alia o lirismo individualista à reflexão sobre o fazer poético e à atenção dirigida ao país real, 
combina a inscrição numa tradição poética com a renovação estética das vanguardas, mostra um poeta português na vivência estética do seu tempo, entre as forças neorrealistas, presencistas e surrealistas (considerando que a colagem foi largamente experimentada por este movimento), conhecendo as várias fontes sem abdicar da sua "voz própria" (Parrado 1996: 194), sem deixar de procurar a sua Terra de harmonia. O retrato aqui não é exatamente o "retrato do artista enquanto reescritor" da sua própria obra, que Rosa Maria Martelo apresenta de modo tão firme (Martelo 2004: 127), apesar de as variações editoriais nos levarem também nesse sentido.

Os versos escolhidos por Carlos de Oliveira incluem palavras recorrentes da sua escrita poética, das quais se destacam "luz" e "lágrimas". A "luz" está especialmente ligada ao próprio ato da escrita e à reflexão sobre Portugal: "escrevendo à luz débil me pergunto / se é a morte ou a manhã que espero" (Oliveira 2003: 34), "escrevo à luz do olvido" (Oliveira 2003: 73), "[a tristeza] fi-la das lágrimas que Portugal chorou / para fazer maior a luz que se avizinha" (Oliveira 2003: 73), "Pego na folha de papel, onde o bolor do poema se infiltrou, levanto-a contra a luz" (Oliveira 2003: 194), "[poema como a estrela tão] cheia / de luz, / que cintila / uma última / vez / e rebenta" (Oliveira 2003: 225), etc. Se o autor Carlos de Oliveira "vi[u] a luz em um país perdido", será que está a referir que foi o país que "iluminou" a sua produção poética, que a provocou ou testemunhou? Ou será que "ver a luz" é aqui perífrase de nascer e que o "país perdido" é afinal o Brasil, e não Portugal? Recorde-se que Carlos de Oliveira nasceu em Belém do Pará e que só com dois anos veio viver para Portugal. A leitura biográfica deste verso pode conter essa ambiguidade: Carlos de Oliveira nasceu de facto no Brasil, mas nasceu como escritor em Portugal. O Brasil é um país perdido politicamente por Portugal e perdido biograficamente por Carlos de Oliveira. Neste sentido nos leva o poema "Carlos Drummond de Andrade" (Oliveira 2003: 188), que usa também o verbo "perder" e fala do "orgulho onomástico / deixado / na outra margem do mar / quando parti / [...] / e silabicamente / me perdi". Não obstante, as possibilidades de leitura do adjetivo "perdido" em relação a Portugal são inúmeras: desde remoto ou disperso a arruinado ou corrupto, várias hipóteses enriquecem o alcance semântico deste verso. Uma leitura mais radical vai no sentido de considerar que o "país perdido" é afinal um país que não existe, o país de qualquer poeta, que tem compatriotas de distintos lugares e tempos. 
A "luz" aparece também no poema de Pedro Mexia, mas com um alcance diferente. No soneto de Camões citado acima, podemos depreender, com a ajuda da dedicatória a Pêro Moniz, que "a luz do dia [ser] escura" é um eufemismo para indicar que o soldado morreu novo, antes de fazer vinte e cinco anos ("não vi cinco lustros acabados"). O verso está, no seu texto de origem, ligado à morte. No poema de Pedro Mexia não podemos afastar este sentido. O "Auto-retrato com versos de Camões" começa com uma declaração fúnebre e continua com desilusão e frustração. A referência a elementos temporais ("cedo", "dia", "anos") mostra o sujeito profundamente atento à passagem do tempo e envelhecido desde o início ("sempre fui bastante velho", Ribeiro 2011), abalado por "errar" em relação "àquilo" em que pôs "tamanho amor". O verbo "errar" pode ser lido com os dois sentidos de "engano" e de "errância" (há aliás outros poemas em que o mesmo campo semântico é explorado), mas o texto não nos dá mais elementos para inferir o que é "aquilo" em que pôs "tamanho amor": uma pessoa?, a própria poesia? Pedro Mexia, perguntando-se em 2011 se escreveria o poema "hoje", responde que "não", reforçando que o poema, "a partir do momento em que está escrito, deixa de estar sujeito à nossa confirmação a cada momento" (Ribeiro 2011). E, nesse sentido, a declaração fúnebre inicial, confirmando a passagem inexorável do tempo, é a declaração de qualquer autorretrato. É também a de Carlos de Oliveira, que começa o poema dizendo que "A cinza arrefeceu sobre o brasido / das coisas não logradas ou perdidas". E recorde-se que estes versos usados por Carlos de Oliveira e por Pedro Mexia são de poetas mortos. Como leríamos os poemas se os títulos fossem, afinal, "Epitáfio do autor por Camilo Pessanha" e "Autoepitáfio com versos de Camões"? Há em ambos os poemas uma alusão forte à morte, mas também ao nascimento ("vi a luz") e à duração do percurso biográfico. Poder-se-ia, então, formular a pergunta de outro modo: e se os títulos fossem "Biografia do autor por Camilo Pessanha" e "Autobiografia com versos de Camões"? Não é agora o momento de explorar as implicações desta hipótese, mas apenas de sublinhar que estes poemas como autobiografias tendem para o autorretrato, graças à súmula biográfica que operam (recordem-se os verbos no pretérito perfeito e imperfeito). Estes poemas, mais do que uma narrativa da história de vida ou de uma inscrição fúnebre, dão-nos uma impressão de vida. E para isso contribui o facto de o título apontar para o retrato e para a leitura de poesia enquanto ato vital. 
São recorrentes na poesia de Carlos de Oliveira as referências a outros poetas, portugueses e estrangeiros, nomeadamente em títulos de poemas: "A Gomes Leal” (Oliveira 2003: 83-84), "Vilancete castelhano de Gil Vicente" (Oliveira 2003: 126), "Soneto castelhano de Camões" (Oliveira 2003: 127), "Sonetos de Shakespeare reescritos em português" (Oliveira 2003: 131-137), “Colagem com versos de Desnos, Maiakovski e Rilke” (Oliveira 2003: 186), "Carlos Drummond de Andrade" (Oliveira 2003: 188), etc. Também Pedro Mexia menciona poetas e outras figuras da história cultural na sua produção, muitas em contexto quotidiano, como o livro que se leva "debaixo do braço": "Wallace Stevens a caminho do escritório" (Mexia 2011: 18), Ernest Hemingway em "Homens sem mulheres" (Mexia 2011: 32), Tchekov em "Futuro radioso" (Mexia 2011: 56), "Ao contrário de Ulisses" (Mexia 2011: 57), Eliot e outras observações (Mexia 2011: 72-88), "Sandokan” (Mexia 2011: 94-95), “Ofélia tornou-se Lady Macbeth" (Mexia 2011: 113), etc.

É, deste modo, relevante que Carlos de Oliveira e Pedro Mexia componham os seus autorretratos com versos de outros poetas, valorizando a tradição em que se inscrevem e ao mesmo tempo afirmando as suas poéticas próprias, de "rarefação" no caso de Oliveira (Rubim 2003), de "deflação elegíaca" no caso de Mexia (recorde-se que a antologia da sua obra recebeu o título Menos por menos e que o seu mais recente livro, Uma vez que tudo se perdeu, insiste na ideia do engano e de um passado com ambições malogradas). Ambos os poemas apresentam um retrato afim de frustrações e desilusões, sendo a própria estrutura semelhante (note-se, por exemplo, que nos primeiros versos a "cinza" e o "brasido" podem corresponder à "escuridão" e à "luz"; que nos segundos versos há uma mesma ideia de desapontamento, de "coisas não logradas" e "esperanças enganadas"). Se para Carlos de Oliveira o elemento-chave é o "país perdido" (qual?), para Pedro Mexia é "[aquilo] em que [pôs] tamanho amor" (o quê?).

Nestes dois poemas, está bem patente a tensão entre pessoalidade e impessoalidade que acompanhou grande parte da produção poética portuguesa ao longo do século XX: o pronome "eu" é figura de linguagem, partilhável, ao mesmo tempo que pode reclamar uma referencialidade autoral. Se a identidade pessoal é definida pela relação de semelhanças e diferenças com o outro, a colagem poética permite jogar com essa relação, problematizando a autoria e transformando formalmente o material poético: são os mesmos versos, mas o 
poema é outro. Não interessa, assim, decidir se os poetas são "fortes" ou "fracos" (cf. Bloom 2007), mas antes observar o modo como são "semelhantes" e "diferentes". Carlos de Oliveira, para explicar por que razão escreve "interpretações doutros poetas", recorre a Aragon (que "imita") e a Pessoa (que "finge"), para concluir que:

Em todo o caso temos consciência, mais ou menos, que a poesia de cada um se faz também com a poesia dos outros no permanente confronto da criação. Para descobrir o que há de pessoal em nós, para nos distanciarmos, já se vê. Mas não se foge completamente a certos contextos literários, a certa parentela. Entramos sempre com maior ou menor conhecimento do facto numa linhagem que nos convém e é dentro dela que trabalhamos pelas nossas pequenas descobertas, mesmo os que se pretendem de uma total originalidade. (Oliveira 2004: 185-186)

O "confronto da criação" é portanto o que está em causa nestes poemas, a integração numa "linhagem" que permite as "pequenas descobertas", que são o que há de "pessoal" em cada autor. Max Ernst, um dos pioneiros da colagem, propõe uma ligação estreita entre o processo dialético da colagem e o conceito de identidade (Adamowicz 1998: 10), declarando, em "Identidade Instantânea", que:

esta troca [aquilo que em linguagem simples se chama "colagem"], seja efectuada como corrente calma e contínua, seja brusca e cheia de relâmpagos, de trovoada, vejo-me tentado a tê-la por equivalente àquilo a que chamam, na filosofia clássica, identidade. (Ernst 1983: 34)

Assim, a colagem poética pode contribuir de um modo muito significativo para definir uma identidade autoral, quer seja em continuidade quer seja em rutura. Se estes poemas são colagens e retratos, são também jogos de "luzes" e de espelhos, "texto[s] diante do espelho" (Oliveira 2004: 185), reflexos de reflexos que reclamam o seu autor. 


\section{Bibliografia}

Adamowicz, Elza (1998), Surrealist Collage in Text and Image, Cambridge, Cambridge University Press.

Allen, Graham (2000), Intertextuality, Londres, Routledge.

Beaujour, Michel (1980), Miroirs d'encre, Paris, Seuil.

Bloom, Harold (2007), A Angústia da Influência (2. ed.), tradução de Miguel Tamen, Lisboa, Cotovia [1973].

Bocchicchio, Maria (2012), "Menos por menos, Pedro Mexia", in Colóquio/Letras, n. 179, Lisboa, Fundação Calouste Gulbenkian, 232-235.

Bowen, C. (2012), "COLLAGE", in Green, R. (ed.), The Princeton Encyclopedia of Poetry and Poetics, Princeton, Princeton University Press, 274 (4. ed.).

Camões, Luís de (1970), Obras de Luís de Camões, Porto, Lello \& Irmão.

-- (1990), Sonetos, Mem Martins, Europa-América.

-- (2003), Poesia Lírica, Lisboa, Dom Quixote.

Campino, Sara (2015), “Colagem: considerações sobre o fragmento em A Âmpola Miraculosa de Alexandre O'Neill”, in Simões, Maria João (coord.), Impressões Surrealistas: o Surrealismo Português entre os Surrealismos Europeus, Coimbra, Centro de Literatura Portuguesa.

Compagnon, Antoine (1979), La seconde main ou le travail de la citation, Paris, Seuil.

Derrida, Jacques (2003), Che cos'è la poesia?, tradução de Osvaldo Manuel Silvestre, Coimbra, Angelus Novus [1988].

Dicionário Houaiss da Língua Portuguesa (2003), tomo III, Lisboa, Temas e Debates.

Ernst, Max (1983), Identidade Instantânea, Lisboa, \& etc [1936].

Ferry, Anne (1996), The Title to the Poem, Stanford: Stanford University Press.

Genette, Gerard (1989), Palimpsestos. La Literatura en Segundo Grado, tradução de Celia Fernández Prieto, Madrid, Taurus [1962]. 
Grande Dicionário da Língua Portuguesa (1949), vol. IX, Lisboa, Confluência (10. a ed.).

Gusmão, Manuel (1981), A Poesia de Carlos de Oliveira, Lisboa, Seara Nova - Comunicação.

Hutcheon, Linda (1989). Uma Teoria da Paródia. Ensinamentos das Formas de Arte do Século XX, tradução de Teresa Louro Pérez, Lisboa: Edições 70 [1985].

Júdice, Nuno (1996), "OLIVEIRA, CARLOS Alberto Serra DE”, in Machado, Álvaro Manuel (org. e dir.), Dicionário de Literatura Portuguesa, Lisboa, Presença, 346.

Martelo, Rosa Maria (1998), Carlos de Oliveira e a Referência em Poesia, Porto, Campo das Letras.

-- (2002), “Anos 90 - Poesia”, in Lopes, Óscar / Marinho, Maria de Fátima (org.), História da Literatura Portuguesa. As Correntes Contemporâneas, vol. 7, Lisboa, Publicações Alfa, 487508.

-- (2004), Em Parte Incerta, Porto, Campo das Letras.

Mexia, Pedro (2007), Senhor Fantasma, Porto, Oceanos.

-- (2011), Menos por menos, Lisboa, Dom Quixote.

-- (2015), Uma Vez que Tudo Se Perdeu, Lisboa, Tinta da China.

Oliveira, Carlos de (1950), Terra de Harmonia, Lisboa, Centro Bibliográfico.

-- (1962), Poesias, Lisboa, Portugália.

-- (1976), Trabalho Poético, vol. 1, Lisboa, Sá da Costa.

-- (2003), Trabalho Poético, Lisboa, Assírio \& Alvim [1976].

-- (2004), O Aprendiz de Feiticeiro, Lisboa, Assírio \& Alvim [1971].

Parrado, Luís Filipe (1996), Por uma Voz Própria. A Questão Intertextual em Terra de Harmonia de Carlos de Oliveira (dissertação de mestrado), Lisboa, Faculdade de Letras da Universidade de Lisboa.

Perloff, Marjorie (1998), "Collage and poetry", <http://marjorieperloff.com/essays/collagepoetry/> (último acesso em 29/02/2016).

Pessanha, Camilo (1995), Clepsydra, Lisboa, Relógio D’Água. 
-- (2000), Clepsydra, in Colóquio/Letras, n. 155-156, Lisboa, Fundação Calouste Gulbenkian. Ribeiro, Anabela Mota (2011), "Pedro Mexia",<http://anabelamotaribeiro.pt/31313.html> (último acesso em 29/02/2016).

Rubim, Gustavo (1998), A Inscrição Espectral. Poética do Vestígio em Camilo Pessanha (tese de doutoramento), Lisboa, Faculdade de Ciências Sociais e Humanas da Universidade Nova de Lisboa.

-- (2003), “A poesia como trabalho", in A Arte de Sublinhar, Coimbra, Angelus Novus, 107121.

Sánchez, Pablo Martín (2012), The Art of Combining Fragments: Hypertextual Practices in Oulipian Literature (Raymond Queneau, Georges Perec, Italo Calvino, Jacques Roubaud), <https://tel.archives-ouvertes.fr/tel-01137503/document> (último acesso a 29/02/2016).

Silvestre, Osvaldo Manuel (1995), Slow Motion, Carlos de Oliveira e a Pós-modernidade, Braga/Coimbra, Angelus Novus.

Teresa Jorge Ferreira (1980) é doutoranda em Estudos Portugueses - Estudos de Literatura na Faculdade de Ciências Sociais e Humanas da Universidade Nova de Lisboa, estando a desenvolver investigação sobre o autorretrato na poesia portuguesa contemporânea, integrada no Instituto de Estudos de Literatura e Tradição, com uma bolsa de doutoramento da Fundação para a Ciência e a Tecnologia. É mestre em Estudos Portugueses - Literatura Portuguesa (Época Contemporânea) pela Universidade Nova de Lisboa (2009) e licenciada em Direito pela mesma Universidade (2003). Foi leitora do Instituto Camões no Chile e em Espanha (2007-2012) e advogada na sociedade PLMJ (2003-2006). Colaborou com Clara Rocha na organização da antologia $A$ caneta que escreve e a que prescreve (Verbo, 2011), promovida pela Fundação Calouste Gulbenkian. Publicou ensaios dispersos e apresentou diversas comunicações sobre literatura portuguesa em Portugal e no estrangeiro. 